\title{
Kur'ân Çalışmalarına Adanmış Bir Ömürr: Prof. Dr. Michel Lagarde ile Tefsir ve Râzî Üzerine Söyleşi
}

ESRA GÖZELER

AR. GÖR., ANKARA Ü. İLÂHIYAT FAKÜLTESI

e-posta: esragozeler@yahoo.com

\section{GiRiş}

Güney Fransa'da küçük bir köyde (Tayrac) fakir bir çiftçi ailenin oğlu olarak 1939 yılında dünyaya geldi. Ailesi ona İbranice "Tanrı gibi olan kimdir?" anlamına gelen Michel ismini verdi. Lagarde bütün çocukluğunu bu kırsal yerde çiftçi ailesi ile birlikte geçirdi. İlkokula ve ortaokula aynı köyde gitti. 11 yaşına bastığında ilk lilâhiyat eğitimini almaya başladı ve rahip olmak amacıyla eğitimini sürdürdü.

Felsefe ve teoloji çalışmalarını Afrika Misyonerleri (White Fathers) Cemaati bünyesinde tamamladı. Rahip olduktan sonra Strasburg Üniversitesi'nde tarih derslerini takip etti. 1984 yılında Lyon II Üniversitesi'nde doktora çalışmasını verdi. Doktora konusu belki de onun ileride yapacağı çalışmalar için dönüm noktası mahiyetindedir. Zira artık Michel Lagarde isminin anıldığı her yerde Râzî akla gelecektir. Lagarde, doktorasında Râzînnin Tefsiru'l-Kebir'in yapısını ve Râzî'nin yorum metodunu Bakara Suresi örnekliğinde ortaya koymaya çalışmıştır. Bu çalışması 1995 yılında Brill tarafından yayımlanan Lagarde'ın şaheseri denilecek Index du Commentaire de Fahr al-Dîn al-Râzî (Tefsiru'l-Kebir İndeksi) için ilk basamak ve bir giriş niteliğindedir. Index için Lagarde on yılın üzerinde çalışmıştır. Eser, Râzî'nin tefsirinin ilk tam indeksi olma özelliğine sahiptir; Râzînin 32 ciltlik tefsirinde yer alan özel isimlerin ve kavramların indeksidir. Bu eser, tefsirin 1981 Beyrut nüshasını esas almaktadır. Ancak 1933 Kahire ve Tahran [t.y] nüshalarıyla da karşılaştırması eserde bulunmaktadır. Index'in mukaddi- 
mesinde metnin önemli ilke terkiplerini ve tefsirî ilke ibarelerini bulmak mümkündür. Eserin en kıymetli özelliklerinden biri de Râzî’nin tefsirinde yer alan usul-i fikh kaidelerinin tefsirdeki yerleri ile birlikte tesbit edilmiş olmasıdır. Index'in mukaddimesi Fransızca, indeks kısmı ise Arapçadır. Daha sonra 2000-2002 yılları arasında, 'Abd al-Qadir al-Jazairi'nin 3 ciltlik eseri Kitâb al-Mawâqifi notları ve yorumları ile birlikte Fransızca'ya çevirmiştir. Şu anda ise Râzînnin estetik anlayışı üzerine "Faydalı Olanın Bittiği Yerde Güzellik Başlar" isimli bir çalışmasını yayımlamak üzeredir. Prof. Dr. Lagarde İslam, Müslüman-Hıristiyan ilişkileri üzerine şu ana kadar yüze yakın telif ve tercüme yapmıştır. ${ }^{1}$ Danışmanı olduğu bütün lisans ve doktora tezlerinde ise konular genel olarak İslam olsa da Râzînnin merkezi bir konuma sahip olduğunu görmekteyiz. ${ }^{2}$

Prof. Dr. Lagarde, İslam üzerine çalışmaya sebep olarak bağlı olduğu dinî cemaati göstermektedir. Zira Afrika Misyonerleri Cemaati, Müslümanlarla karşılaşma konusunda çalışmaktadır. Özellikle çalıştıkları bölge Kuzey Afrika'da Müslüman nüfusun daha çok olduğu kısımdır. Prof. Dr. Lagarde kısa sürelerle Tunus, Cezayir, Fas, Filistin ve Yemen'de bulunmuştur. Ayrıca Mali, Bangladeş, Endonezya, Malezya, Singapur ve Jibouti gibi Müslüman çoğunluğun bulunduğu ülkeleri de ziyaret etmiştir. Arap kültürüne yapmış olduğu katkılardan dolayı 2005 yılında UNESCO tarafından verilen "Sharjah Arab Kültürü" ödülünü kazanmıştır.

Prof. Dr. Lagarde, Arapça ve İslam üzerine çalışmalarına Roma'da Vatikan'a bağlı Arap ve İslam Araştırmaları Enstitüsü'nde (PISAI) başlamıştır. ${ }^{3}$ PISAI, Afrika Misyonerleri Cemaati tarafından kurulmuş; İslam ile karşılaşan Hıristiyanların formasyonunu üstlenmiş bir enstitüdür. Öğrencileri arasında çoğunlukla Müslüman veya nüfusun çoğu Müslüman olan ülkelerde görev yapacak olan rahipler olmasına rağmen İslam üzerine çalışmak isteyen ve din sınıfından olmayan öğrencileri de mevcuttur. Amacı karşılıklı saygı ve anlayış ruhu içerisinde Hıristiyanları İslam konusunda eğitmektir. Bu amaçla 1975 yılından bu yana Islamochristiano: Dirâsetun İslamiyyetun Mesîhiyye adıyla yıllık akademik bir dergi de yayımlamaktadır. Bu enstitüde verilen dersler İslam ve Arap Dili olmak üzere iki ana dalda ve toplam üç yılda verilmektedir. ${ }^{4}$ Prof. Dr. Lagarde, ikinci yıl Arap Dili dalında

1 Ek 1'de Prof. Dr. Michel Lagarde'ın telif ve tercüme eserlerinin bir listesi sunulmuştur.

2 Ek 2'de Prof. Dr. Michel Lagarde'ın danışmanlık yaptığı tezler verilmiştir.

3 PISAI, İtalyanca Pontificio Istituto di Studi Arabi e D’Islamistica'nın baş harflerinden oluşmaktadir.

4 Birinci yıl Kahire'de, ikinci ve üçüncü yıllar ise Roma'da tamamlanmaktadır. Öğrencilerin aldığı dersler şöyledir: Birinci Yıl: Giriş: İslam'ın Panoraması; İslam'ın Doğuşunun Tarihsel ve 
Kur'ân ve Arapça Gramer derslerini; üçüncü yıl ise Klasik Tefsir Metinleri ve Hadis derslerini vermektedir.

Prof. Dr. Lagarde sahip olduğu mükemmel Arapça formasyonunu nerede ve nasıl elde ettiği sorusuna da büyük bir onurla Arapça hocasının kendisi gibi bir Fransız ve uzun yıllar PISAI'de dersler vermiş olan Prof. Dr. Maurice Borrmans olduğu cevabını verir. Cep telefonu kullanmayan ve bir elektronik posta hesabı olmayan Lagarde hayatını bütün otantikliği ile yaşamaktadır. Kendisi ile iletişim kurmak isteyenlere ise Enstitü'deki çalışma ofisinin numarasını ve mektup adresini vermektedir. Roma'da uzun süre öğrencisi olduğum ve kendisinden Klasik Tefsir Metinleri dersini aldığım Prof. Dr. Michel Lagarde ile dersler esnasında tartıştı̆̆ımız Kur'ân, Tefsir, Râzî ve Müslüman-Hıristiyan ilişkileri ile ilgili fikirlerini ve eserlerini Türk okuyuculara tanıtmak amacıyla, aşağıdaki mülakatta ${ }^{5}$ özet bir şekilde ortaya koymaya çalıştık.

\section{Tefsir ve Kur'ân}

Esra Gözeler: Tefsir'i nasıl tanımlıyorsunuz? Size göre tefsirin anlamı nedir?

Michel Lagarde: Tefsir, müfessir kim olursa olsun her zaman Kur'ân'ın deneme türünden açıklamasıdır. Her müfessirin kendi doğal eğilimleri ve ideolojik ilgileri bulunmaktadır. Tefsiri meydana getiren olgu, müfessirler arasında farklı şekillerdedir. Örneğin Zemahşeri, Taberi ile Kur'ân tefsiri açısından aynı yaklaşıma sahip değildir. Bunu geliştirilmesi gereken geniş bir konu olarak görmekteyim.

Esra Gözeler: Sizin tefsir tanımlamanıza göre en iyi tefsir hangisidir?

Michel Lagarde: Benim için Râzînnin tefsiri şu ana kadar okuduğum en iyi tefsirdir.

Coğrafi Bağlamı; Hz. Muhammed'in Hayatı; Kur'ân: Tanıtımı, Muhtevası, Metnin Tarihi, Ana Konuları; Sünnet: Kökeni, Anlamı, Koleksiyonlar, Yapı; Halifeler; Emeviler; Abbasiler; Haçlı Seferleri; Osmanlılar; Müslüman Akaidi, İslam'ın Esasları; İslam Teolojisine Giriş; İslam Mistisizmine Giriș; İslam Hukukuna Giriș; Çăgdaș İslam: Eğilimler, Akımlar, Yazarlar; Modern Dünyada İslam: Avrupa, Afrika, Asya, Yakın Doğu; Müslüman-Hıristiyan Diyaloguna Giriş; Arapça. İkinci ve üçüncü yıllarda, birinci yılda giriș mahiyetinde alınan dersler daha derin bir şekilde klasik metin okuma usulüyle incelenmektedir. İkinci Yıl: Çağdaş İslam; İslam Teolojisi; İslam Felsefesi; Şii İslam; İslam Geleneği; İslam Hukuku; İslam Mistisizmi; Tarih; MüslümanHıristiyan İlişkilerinin Tarihsel ve Teolojik Yönleri; Arapça. Üçüncü Yıl: Metodoloji; Klasik Tefsir Metinleri; Felsefi Metinler; İslam teolojisi; Edebiyat; Hukuki Metinler; Hadis; Çağdaş Tefsir Metinleri; Tarihi Metinler; Tasavvufi Metinler; Apolojik Metinler.

5 Mülakattaki soruların büyük kısmı Prof. Dr. Lagarde'a yazılı halde İngilizce olarak takdim edilmiştir. Prof. Dr. Lagarde soruları Fransızca cevaplandırmış; Enstitü asistanlarından Felix Phiri, M. Afr. tarafından İngilizceye çevrilmiştir. İngilizce çeviriyi Prof. Lagarde gözden geçirmiştir. Bu vesile ile İngilizce tercüme için Felix Phiri'ye, M. Afr. teşekkür ederim. 
Esra Gözeler: Son zamanlarda Tefsir üzerine yapılan çalışmaları nasıl değerlendiriyorsunuz?

Michel Lagarde: Çağdaş Tefsir açısından, ölmeden önce son zamanlarda televizyonda Kur'ân tefsiri yapan Misırlı Şa'ravi'den oldukça okudum. Onun yaklaşımını kültürel ve manevi açıdan oldukça zayıf, hakiki kültürel ve manevi boyutlardan yoksun bulmaktayım. Bu, Kur'ân'ı günün ihtiyaçlarına göre alınan ilaç gibi gören bir imajdır. Seyyid Kutup, gerçek Kur'ân müfessiri olarak addedilmek için mücadeleci ideolojiden oldukça etkilenmiştir. Menar, bazı ilginç yönlere sahip olmasına rağmen düşünsel ve ruhani linguistik boyuttan uzaktır.

Esra Gözeler: Bir dersimiz esnasında Muhammed Hamidullah'ın Kur'ân çevirisinde yapmış olduğu bir hatayı düzeltmiş olduğunuzu hatırlıyorum. Bütün çeviriyi bu gözle okudunuz mu; zikrettiğiniz şekilde başka hatalarda buldunuz mu?

Michel Lagarde: Bu soruyu cevaplandırmak benim için çok kolay değildir. Çünkü cevabı uzun açıklamalar gerektirmektedir. Temel olarak, bildiğim bütün Kur'ân çevirileri genellikle hatalıdır ve hakikatten oldukça farklıdır; doğru olanlar ise şık değildirler. En azından Fransızca açısından durum böyledir.

Esra Gözeler: Kur'ân'ı Fransızca'ya tercüme etmeyi düşünüyor musunuz?

Michel Lagarde: Kur'ân'ın sadece Arapça okunabileceği konusuna derinden inanmaktayım. Hiçbir zaman başka bir dile çevirmeyi düşünmedim. Kur'ân metni, Arapça olarak daha çekicidir. Çevrildiği zaman ise daha sıkı$\mathrm{c}$, cansız ve yavan hale dönüşmektedir.

Esra Gözeler: Kur'ân'da sizi etkileyen ayetler var mıdır?

Michel Lagarde: Kur'ân'da mutlaka beni etkileyen birçok ayet bulunmaktadır. Burada sadece iki tanesini zikredeceğim. Bunlar: 2, Bakara Suresi 256: "Dinde zorlama yoktur; artık hak ile batıl iyice ayrılmıştır..."; 30, Rum 22: "Gökleri ve yeri yaratması, dillerinizin ve renklerinizin değişik olması O'nun varlığının belgelerindendir. Doğrusu bunlarda, bilenler için dersler vardır." Daha farklı birçok ayette zikretmek mümkündür.

\section{Fahruddin er-Râzî}

Esra Gözeler: Kaç yıl Râzînnin Tefsiri üzerine çalıştınız?

Michel Lagarde: 1980 yılında Râzî çalışmaya başladım.

Esra Gözeler: Neden çalışmak için Râzîyi seçtiniz? Sizin için Râzînin ayırt edici özelliği nedir? Râzî̀yi diğer müfessirlerden ayıran nedir?

Michel Lagarde: Bu müfessiri seçmemin sebebi onun eserinden daha birkaç pasaj okuduktan sonra ancak onun benim İslam'ı içeriden ve çok 
daha zengin bir bakış açısıyla kavramamı sağlayabileceğini anladım. Aynı zamanda, daha sonra, Râzînnin bana Müslüman hassasiyetine erişmek aç1sından anahtarlar sunduğunu gördüm. Râzînin bütün Tefsirini iki kez okudum ve bunu hayatımın en temel tecrübelerinden biri olarak saymaktayım.

Râzî birçok sebepten dolayı benim için ilginçtir: (1) O, zeki ve çok kültürlü biridir. (2) Eseri ansiklopedik bir eserdir ve bu yüzden bana İslam dini hakkında hem kesin hem de global bir vizyon kazandırmıştır. (3) Râzî, kendisini bağlayacak şekilde fikirlerini söylemektedir ve kişisel görüşünü vermekten korkmayan biridir; bunu da büyük bir orijinallik ve yaratıcılıkla yapmaktadır. Taklitten ise nefret etmektedir. (4) Râzî, Kur'ân metnini içtenlikle seven biridir. Ayrıca tahrik edici biri olmanın ötesinde muazzam keşiflerini ve ayetlerle ilgili şaşkınlığını aktarmak isteyen biridir. (5) Râzî, dürüst bir aydındır. Çünkü Kur'ân metninde yer alan hiçbir zorluğu gizlememektedir. Özellikle, örneğin Kâdî Abdulcebbar gibi, kendi düşünce ekolünden olmayan insanları küçümsememektedir. (6) Râzî sadece entelektüel biri değil aynı zamanda ruhani biridir. Büyük ihtimalle İbn Arabi'den etkilenmiştir. Râzî̀nin yorumundaki derinliği ekseriya şaşırtıcıdır ve bugün hâlâ lezzet vericidir. Hatta Müslüman olmayanlar için bile. (7) Râzî içten bir insan; son derece duygusal bir babadır. Birçok sure tefsirinin sonunda okuyucudan bir savaş esnasında vefat eden oğlu için dua istemektedir. Bu dua istemine denk geldiğim her seferinde Râzînnin oğlu için dua ediyorum. Çünkü kendimi onun babasına çok tutkun hissediyorum. Ben bu maceraya İslam ile ilgili öz bir eğitim aramak amacıyla girdim. Ve sonunda canı ve kanıyla Müslüman ve yaşayan, diri bir insan ile karşılaştım.

Zamahşeri'yi yaptığı lingusitik açıklamalardan dolayı çok beğenirim. Aslında Râzî de sık sık ona atıflarda bulunmaktadır. Ayrıca Kurtubi'yi Kur'ân metni üzerinde, özellikle Mukaddimesinde yaptığı, orijinal ve cesur değerlendirmelerinden dolayı beğenmekteyim. Taberi'nin rivayet zenginliği açısından değerini çok takdir etmekteyim. Ancak bütün bu müfessirlerde kültürlü, entelektüel ve ruhani olan Râzî̀nin büyük etkisini bulmamaktayım.

Esra Gözeler: Râzînnin tefsirinin Müslüman dünya tarafından yeteri kadar takdir edildiğini düşünüyor musunuz? Eğer edilmiyorsa sizce bunun sebebi ne olabilir?

Michel Lagarde: Genel olarak Müslüman dünyanın Râzî̀yi bu kadar az okuyup çalışmasının beni çok şaşırttı̆̆ını söylemeliyim. Nedenini gerçekten bilmiyorum. Muhammed Abduh'un bir seferinde "Râzî”nin tefsirinde Kur'ân tefsirinden başka her şey vardır" dediğini biliyorum. Ancak kaynağı 1 gösterilmeksizin birçok yerde Râzî’nin etkisini Menar'da bulmak mümkün- 
dür. Çağdaş Müslüman düşünürlerin ortaçağdaki bir düşünceyi yeniden diriltmek konusunda ketum ancak çağdaş batılı düşünceye doğru daha eğilimli olmaları mümkün müdür? Açıkça Râzîyi bugün yinelemek yeterli değildir. Yine de eğer biri Râzî’nin duruşundan ve derin sezgilerinden esinlenmiş olursa Râzînnin ihtişamlı bir şekilde kendi zamanı ve kültürel çevresi için yaptığg gibi Kur'ân metnini bugüne uygun sunma yolunu bulmuş olur. Birçok Müslümanın imanını ve Kur'ân'a yaklaşımını beslemek için kendisini -bana oldukça yetersiz görünen- Celaleyn ve Beydavi tefsirleri ile sınırlandırması çok yazıktır.

\section{Afrika Misyonerleri (White Fathers) Cemaati}

Esra Gözeler: Afrika Misyonerleri Cemaatine katılmaya nasıl karar verdiniz?

Michel Lagarde: Afrika Misyonerlerine katıldım; çünkü 18 yaşındayken Afrika'da yaşamak ve çalışmak bana çok cazip gelmişti.

Esra Gözeler: Afrika Misyonerleri Cemaati ile ilgili çok kısa bilgi verebilir misiniz?

Michel Lagarde: Afrika Misyonerleri, 1868 yılında Cezayir'de, başpiskopos iken Kardinal Lavigerie tarafindan kurulmuştur. O dönemde, Kuzey Afrika'daki kilise ile Fransız kolonileri ilgilenmekteydi. Kardinal Lavigerie, kendisinin pastoral ilgilerinin bir parçası olarak Müslümanlara karşı özel bir ihtimam fikrine sahipti. Bu sebepten yola çıkarak bu cemaati kurmuştur. ${ }^{6}$

Esra Gözeler: Rahip olarak görev yaptınız mı?

Michel Lagarde: 9 yıl Mali'de 3 yıl da Fransa'da rahip olarak çalıştım. Şu anda PISAI'de profesör olarak çalışmaktayım ama aynı zamanda rahibim.

\section{Müslüman-Hıristiyan Ilişkileri}

Esra Gözeler: Müslüman dünyayı nasıl görüyorsunuz? Sizce biz Müslümanlar Kur'ân'ı anlayıp uygulayabiliyor muyuz?

Michel Lagarde: Bu konuda genel bir değerlendirme veremem zira bu soruyla ilgili olarak yeterince bilgiye sahip değilim. Konuyu özetlemek ise onu tam olmayan ve aslından farklı bir hale getirecektir.

6 Cemaatin kurucusu Kardinal Lavigerie üç temel prensip yerleştirmiştir: 1. Onların dilini konuşacaksın; 2. Onların yemeğini yiyeceksin; 3. Onların giydiğini giyeceksin. Bu cemaate "White Fathers" denilmesinin sebebi rahiplerin tenlerinin beyaz olması değil; Kardinal'in prensibine uygun olarak Afrika'daki erkeklerin giyindiği gibi beyaz ve uzun elbiseler giyinmiş olmalarındandır. Daha fazla ayrıntı için http://www.mafroma.org/ adresine bakılabilir. 
Esra Gözeler: Şu anda Müslüman-Hıristiyan ilişkilerini nasıl görüyorsunuz?

Michel Lagarde: Müslüman-Hıristiyan ilișkileri hiçbir zaman kolay olmamıştır. Daha ziyade sanki bugün siyasi çıkarlar şiddetlendirilmiştir. Bana gelince, her ne kadar mütevazı ve sınırlı olsa da böyle bir ilişki içerisine girerim. Bunu ise Arap-Müslüman dünyaya çalışkan, dikkatli, kültürel ve manevi bir dalış ile yapmaya çalışıyorum. Bu planı izleyeli yaklaşık olarak 30 yıl oldu. Bu sayede dışardan biri olarak bu çevre için büyük bir saygı ve hayranlık duygusu kazandım. Eğer biri ötekilerle çok belirsiz ve çok şüpheli olmayan bir ilişkiye girebilirse ancak bu şekilde onların ötekiliğine saygı duyacağına ve takdir edeceğine inanmaktayım.

Esra Gözeler: Sorularıma sözlü ve yazılı verdiğiniz cevaplara ayırdığınız zamandan dolayı teşekkür ediyorum.

EK (1)

\section{PROF. DR. MICHEL LAGARDE'IN ESERLERI}

1977, Hadîth qudsiyya: extraits de l'ouvrage Al-Ahâdîth al-qudsiyya, le Caire 1969-70, 2 vols./rassemblés et traduits par Michel Lagarde, Kahire.

1978, Enquête sur le sens donné par les Commentateurs du Coran et le Hadîth au mot Rûh, Roma.

1979, Quelques aspects concrets du dialogue islamo-chrétien au Mali [Afrique de l'Ouest], Kahire.

1979, Nûr al-albâb: Le livre de la lumière des coeurs/du Shaykh 'Uthmân b. Muhammad b. 'Uthmân connu sous le nom de Ibn Fûdî, traduit par Michel Lagarde, Kahire.

1980, Dossier sur la magie en Islam: 1re partie, Kahire.

1981, Al-Tafsîr al-Kabîr/al-Râzî, traduit et présenté par Michel Lagarde, Kahire.

1981, Al-'adâla l-ijtimấiyya fíl-islâm/Sayyid Qutb, traduit par Michel Lagarde, Kahire.

1981, Ma'rakat al-islâm wa l-ra'smâliyya/Sayyid Qutb, traduit par Michel Lagarde, Kahire.

1982, Qâdat al-haraka l-islâmiyya l-mu'âsira: Chefs de file du mouvement islamique contemporain / Rashîd al-Ghannûshî, traduit par Michel Lagarde, Kahire.

1982, L'unité arabe/Michel 'Aflaq, traduit par Michel Lagarde, Kahire.

1983, Khandaq wâhid am Khandaqân?: Problèmes du Front National et Progressiste/Saddâm Husayn, traduit par Michel Lagarde, Kahire.

1984, Essai De Planification Et D'indexation Du Texte Du Commentaire De La ème Sourate Du Tafsîr De Fakhr Al Dîn Al Râzî, Lyon: U.E.R. des Langues et Civilisations du Monde Méditerranéen.

1984, Tawsiyyât al-Nadwa l-islâmiyya al-âlamiyya : al Islâm fí Afrîqiyâ: Recommandations du 11ème séminaire islamique mondial sur l'islam en Afrique/traduit par Michel Lagarde, Kahire.

1984-1985, Définition du Tafsîr d'après al-Suyûtî, Kahire.

1984-1985, I'râb al-Qur'ân: Chapître comprenant les pronoms du texte révélé: quel est leur antécédent ?/al-Zajjâj, traduit par Michel Lagarde et Sâmih Faragallah, Kahire. 
1984-1985, Al-Tafsîr al-kabîr [Mafâtîh al-ghayb]: Les noms qui conviennent à Dieu. Chapître des pronoms/Fakhr al-Dîn al-Râzî, traduit par Michel Lagarde, Kahire.

1985, Recherche intellectuelle et dialogue islamo-chrétien, Roma: Pontificia Universitas Urbaniana.

1985, Rûh al-ma'ânî: La liberté religieuse/Abû al-Thanâ' al-Alûsî, traduit par Michel Lagarde, Kahire.

1985, Tafsîr al-Qur'ân al-Karîm: Les circonstances de la révélation/Muhammad al-Tâhir Ibn 'Ashûr, traduit par Michel Lagarde, Kahire.

1985, Al-Tafsîr al-ilmi: Le commentaire "scientifique" du Coran: comparaison entre les découvertes coraniques contenues dans les versets relatifs aux astres et les découvertes de la science moderne/Ahmad Hanafî, traduit par Michel Lagarde, Kahire.

1985, Al-Dhikr al-hakîm: L'inimitabilité du Coran/Kâmil Husayn, traduit par Michel Lagarde, Kahire.

1985, Definition des concepts de Muhkam et de Mutashâbih dans le commentaire coranique, Roma: PISAI.

1985, Magia arabo-musulmana e mentalità moderna/Michel Lagarde et Sameh Faragallah, traduzione italiana di Rosa M. Benatti, Tifeo.

1988, Influences de l'Arabe sur la Langue Bambara, Falaje (Mali).

1989, Al-tajdîd wa-l-mujaddidûn: Le renouveau et les rénovateurs/Ahmad Amîn, traduit par Michel Lagarde, Kahire.

1989, Position de Fakhr al-Dîn al-Râzî sur le mariage et la vie consacrée, Kahire.

1990,Akhbâr Makka: Le temple primordial/Abû l-Walîd Muhammad al-Azraqî, traduit par Michel Lagarde, Kahire.

1990, Commentaire sur la sourate "al-Baqara”, verset 114 / Fakhr al-Dîn al-Râzî, traduit par Michel Lagarde, Kahire.

1991, Les juifs et les chrétiens sous les 'abbasides/Ahmad Amîn, traduit par Michel Lagarde, Kahire.

1991, Commentaire du Manâr sur la sourate "al-tawba": verset 29/Rashîd Ridhâ, traduit par Michel Lagarde, Kahire.

1992, La raison chez Fakhr al-Dîn et la pensée chez Blaise Pascal, Kahire.

1992, Les dangers de l'orientalisme et notre façon de les affronter/traduit par Michel Lagarde, Kahire.

1992, Du mérite des orientalistes dans la renaissance de la pensée islamique/Ahmad Hussayn, traduit par Michel Lagarde, Kahire.

1992, Violence et Vérité: Etude de textes islamiques, Kahire.

1992, Les dangers de l'orientalisme et notre façon de les affronter/'Abd al-Latîf al-Shuwayrif, traduit par Michel Lagarde, Kahire.

1992, La Visite [Des Tombeaux] Et Les Questions Qui S'y Rapportent/Ahmad İbn Taymiyya, traduit Par Michel Lagarde, Kahire.

1992, Fadl al-mustashriqîn 'alâ nahdat al-fikr al-islâmî : Du mérite des orientalistes dans la renaissance de la pensée islamique/Ahmad Husayn, traduit par Michel Lagarde, Kahire.

1992, La pace secondo il Corano, Paris: Edizioni d'Europa.

1993, Prescriptions de Dieu et son envoyé concernant les imâms/Muhammad al-Kulayni, traduit par Michel Lagarde, Roma: PISAI.

1996, Index du Grand Commentaire de Fakhr al-Dîn al-Râzî, Leiden : E.J. Brill.

1996-1997, La laïcité et l'Occident/'Umar 'Abd Allâh Kâmil, traduit par Michel Lagarde, Kahire. 
1996-1997, Pour humaniser l'Islam: la laïcité/'Alî Harb, traduit par Michel Lagarde, Kahire. 1997, Islam e postmodernità, Roma.

1997, L'Islam n'est pas un bloc monolithe, Kahire.

1997, Rivelazione e profezia secondo l'Islam e il cristianesimo, Torino: Edizioni Mille Libri.

1997, Chiesa e Musulmani in Italia : dialogo interreligioso e annuncio cristiano/F. Ardusso, C. Collo, S. Khalil Samir, M. Lagarde, A. Negri, Torino: Edizioni Mille Libri.

1998, Le mouvement soufi/extrait du journal al-Ahrâm sous la direction de Nabîl 'Abd alFattâh, traduit par Michel Lagarde, Kahire.

2000, Un exemple de la position akbarienne sur le Jihâd, Città del Vaticano: Archivio Segreto Vaticano.

2000, Le livre des Haltes/'Abd al-Qâdir al-Djazâ'irî, Kitâb al-Mawâqif - Tome I; Présenté, traduit et annoté par Michel Lagarde, Leiden : Brill .

2001, Le livre des Haltes/'Abd al-Qâdir al-Djazâ'irî, Kitâb al-Mawâqif- Tome II; Présenté, traduit et annoté par Michel Lagarde, Leiden: Brill.

2002, Le livre des Haltes/'Abd al-Qâdir al-Djazâ'irî, Kitâb al-Mawâqif- Tome III; Présenté, traduit et annoté par Michel Lagarde, Leiden: Brill.

EK (2)

\section{PROF. DR. MICHEL LAGARDE'IN DANISSMALIK YAPTIĞI TEZLER}

1981, Sanou, Lucas, Abû Hâmid Muhammad b. Muhammad al-Ghazâlî: du merite de l'anitie (ulfa) et de la fraternite (ukhuwwa) en Dieu: leurs conditions, leurs avantages. Extrait de l'Ihya' 'ulûm al-dîn.

1982, Ayuso, Miguel, Sayyid Qutb 1966. Un contributo alla conoscenza dei Fratelli Musulmani. Salâm al-damîr (la pace della coscieenza), estratto dal labro "al-Salâm al 'âlamî wa'l-Islâm" (La pace mandiale e l'Islam).

1982, Yameogo, Alexis-Desire, 'Uthman Dan Fodio: Bayân al-bid'a al-Shaytâniyya allati ahdathaha al-nâs fí abwâb al-milla al-muhammadiyya (Enumaration des innovations sataniques que les gens ont inventees das les domaines de la religion musulmane).

1983, Dore, Fillipo, La superiorita della Sapienza in Fakhr al-Din al-Râzî, Kitâb al-Tafsîr alkabîr; commento al versetto coranico 2/31, par. II, pp. 178-193, righe 1-417.

1983, Intartaglia, Celeste, Sirâj al-Ikhwân fi ahamm mâ yuhtâju ilay-hi fi hâdha'l-zaman, (La fiaccola dei fratelli sulle case piu importanti di cui si lo bisogno in questi tempi di 'Uthman ibn Fûdî (Don Fodio).

1984, De Angelis, Fina, Dualismo. Proposta di filosofia araba contemporanea di Zâkî Najîb Mahmud.

1984, Michau, Jean Pierre, Commentaire de la sourate 2, verset 163, de Fakhr al-Dîn al-Râzî (Trate sur le Tawhid. Traduction avec notes et glossaire).

1990, Lane, Andrew, Ikhtilaf al-qirâ'ât fi suwar al-anbiyâ. Compilation and commentary on the variations of Korani Reading in the al-Tafsir al-Kabir of Fakhr al-Din al-Râzî.

1992, Bajerowigz, Maciej, Fakhr al-Dîn al-Râzî̀'s Concept of Language Presented in his Great Commentary of the Qur'an.

1992, Gallo, Maria, Il Dio uno nel commento di Fakhr al-Dîn al-Râzî al Corano 2, 163.

1992, Impagliazzo, Chiera, Traduzione e note in margine ad uno scorcio del tafsîr di Fakhr al-Dîn al-Râzî.

1992, Nuyombi, Richard, Three Sermons on The Gihâd. 
1993, Ferraboshi, Davide, L'introduzione decima di Muhammad al-Tâhir İbn Âshûr sula natura miracolosa del corano.

1993, Liling, Bartho, Fakhr al-Dîn al-Râzî 1210. "Fi bayân al-istidlâl bi ahwâl al'ard 'alâ wujûd al-Sâni". The explanation of the demonstration of the existence of the Creator through the States of the Earth.

1993, Vezoli, Davide, I valoci degli atti umani nella teologia musulmana. Traduzione e commento al capitolo sesto del Ma'âlim di Fakhr al-Dîn al-Râzî.

1997, Budelli, Rosanna, La concisione a la metafora nel "Kitâb al-nukat fi i’jâz al-Qur'ân" di Abû Ibn 'Îsâ al-Rumânî.

1997, Cottini, Valentino, L'impeccabilita di Abramo nella 'Ismat al-Anbiya' di Fakhr al-Dîn al-Râzî.

1997, De La Hougue, Henri, Ibn Kathir 'Imâd al-Dîn 1373. La Sourate de l'Etoile. Traduction et commentaire d'Ibn Kathir.

1998, Bogne, Raymond, Commentaire sur les situations des minorites musulmanes dans le continent Africain selan 'Abn al-Rahmân Muhammad Hasan Sumâr al-Dhahab.

1998, Monendotti, Serenella, 'Abd al-Qâdir al-Jazâ'iri 1883. 'Kitâb al-Mawâqif': Libro dele fermate sulla mistica, la predicazione e la guida dell'Emiro 'Abd al-Qâdiral-Jazâ'iri.

1998, Prakosa, Heru, Theory of Abrogation (naskh) according to Fakhr al-Dîn al-Râzî based on Qur'ân 2/100-106.

1999, Fiorentini, Alessendra, Fakhr al-Dîn al-Râzî; al-Tafsîr al-Kabîr.

1999, Ghica, Victor, Sermon arabe inedit attribue a Shenute.

1999, Gobbi, Ruffino, Commento al versetto 23 della sîna 2 del Corana in "Al-Tafsir al-Kabîr di Fakhr al-Din al-Râzî all'interno del dibattito sull'inimitabilita del Corano (i'jâz alQur'ân).

1999, Russo, Giovanni, Sayyid Qutb: Commento alla Sura 5, versetti 27-40.

1999, Zappa, Francesco, La Magio vista da un esegeta del Corano: il Commento di Qurtubi al versetto II, 102.

2000, Corullon, Fernandez, El Compasivo, el Misericordioso: Analisis des dos Nombres Divinos.

2000, Kasozi, Kiwanuka, The Primacy of the Verse al-Kursî in the Qur'ân: An Analysis of Fakhr al-Dîn al-Râzî.

2000, Maffi, Gian Battista, La Metafora della Luce: Il Commento al "Versetto dello Luce" (Corano: 24, 35) li Fakhr al-Din al-Râzî.

2000, Macnamara, Paula, Dialogue or Clash: A Study of chapter from sîkûlûdjîa al-'unf wa strâtidjîa al-'amal al-silmi (Psychology of Violonce and Peace Process)/Dr. Hâlis Jalabi.

2000, Taiwo, Segun, Some Names and Attributes of God: Translation and Commentary of Râzî̀'s Tafsir al-Kabîr/vol. 1, pages 284-290.

2001, Haddad, Hanan, I temrini tecnici di "ta'arud, tanâqud e tafâwut" nel commento del Râzî.

2004, Delmas, Bruno, La vision de Dieu selon le commentaire du Manâr (2. danışman).

2004, Leon, Blanco Jesus Manuel, La Aleya de la Distribucion de las Limosnas.

2005, Alaniz, Gonzalez Hugo Fabian, La creacion de los actos del hombre segun la vision ash'arita del Fakhr al-Dîn al-Râzî.

2005, Conde, Sebastian, Les Secrets de la Revelation concernant la Parole: "Il n'y a de divinite que Dieu”, selon Fakhr al-Din Muhammed Ibn 'Umar Ibn al-Husayn al-Râzî.

2005, Schelling, Thierry, Al-'Adl, pilier de la thelogie mu'tazilite; quelques arguments moraux et psychologi ques tires du Sharh al-usûl al-khamsa de 'Abd al-Jabbâr. 
2005, Solo, Kewuta Markis, Reflection the Benefits of Lâ ilâha illâ Allâh according to the Imâm Fakhr al-Din Muhammed b. 'Umar b. Al-Husayn b. Al-Râzî.

2005, Songre, Pierre, Surles noms de la formule de la Profession de foi selon Fakhr al-Din alRâzî.

2006, Basanese, Laurent, La Sagesse De La Creation De l'Homme. Traduction et Commentaire du chapitre Hikmat halq al-insân extrait de: al Hikma fi mahluqat Allâh 'azza wa jalla La sagesse dans les creatures de Diew tout-puissant) de Abû Hamid al-Gazâlî.

2006, Massimo, Rizzi, Marracci Rilegge Al-Zamahsharî.

2006, Cucarella, Diego R. Sarrio, Una Lectura Cristiana Del Coran? (La Respuesta De Ibn Taymiya a Pablo de Antioquia).

2006, Prakosa, Heru, Meaning in the Order of Discourse and an Attempt to Approach it: A Study on Al-Râzî̀'s Nihâyât al-Îjầz fì Dirâyât al-I'jâz.

2007, Guillaume Michel, Le traité d'herméneutique coranique de Fahr al-Dîn al-Râzî dans le commentaire du verset 7 de la sourate 3 du Tafsîr al-Kabîr: la question du muhkam et du mutasâbih. 